\title{
Kocuria rosea
}

National Cancer Institute

\section{Source}

National Cancer Institute. Kocuria rosea. NCI Thesaurus. Code C86469.

A species of Gram positive, cocci shaped bacteria assigned to the phylum Actinobacteria.

This species is oxidase and indole negative, nonencapsulated, non spore forming,

nonhemolytic, benzidine positive and saprophytic. K. rosea is part of the normal flora of the skin but may have pathogenic potential in surgical patients. 